\title{
HUBUNGAN SUMBER INFORMASI KESEHATAN REPRODUKSI DENGAN PERILAKU SEKSUAL PADA PELAJAR SMA NEGERI DI KOTA SABANG TAHUN 2015
}

\author{
Yuni Dewi Safrida ${ }^{1}$, Gerry Silaban ${ }^{2}$, Ns. Selamat Ginting ${ }^{3}$ \\ ${ }^{1}$ Alumni Program Studi S2 Ilmu Kesehatan Masyarakat STIKes DHDT \\ ${ }^{2}$ Staf Pengajar Program Studi Ilmu Kesehatan Masyarakat USU \\ ${ }^{3}$ Staf Pengajar Program Studi Ilmu Kesehatan Masyarakat STIKes DHDT
}

\begin{abstract}
Source of information obtained teenagers about reproduction health is pushed the behavior of the teenagers to know more about sexual problem. In line with the era of globalization, information and technology, there is a big change in the sexual behavior of teenagers. Unwanted pregnancy, unsafe abortions and an increase in cases of sexually transmitted infections, which is a problem in teenagers reproduction health in Indonesia. The results of research in the program of Muda Berkarya conducted by Yayasan Kita (2005), teenagers of Sabang and some other town in the province of Aceh are likely to be further involved in unsafe sexual behavior. The purpose of this survey study with cross sectional study design is to examine the relationship of reproduction health resources (role of media, role of parents, role of peers) on the sexual behavior of high school students in Sabang. The population of this study are 607 high school students and 113 of them were selected through univariate proporsional hypothesis test to be the samples for this study and bivariate (Chi square test) with significance level $\alpha<0,05$ and level of confidence of 95\%. The results using Chi square test shows that significant variables related to sexual behavior are: the role of the media $(p=0.018)$ role of parents $(p=0.043)$ and the role of peers $(p=0.014)$. All of these variables have been associated with sexual behavior. It is suggested that the Department of Health to improve the implementation of outreach programs Teenagers Reproduction Health. With the counseling of students to better understand and care for reproduction health. The Department of Education to improve reproductive health education curriculum, so that students are better able to keep the negative sexual behavior and pornography so that negative interactions can be avoided.
\end{abstract}

Keywords : Sources of information, reproduction health, sexual behavior

\section{PENDAHULUAN}

Idealnya remaja telah memperoleh pengetahuan yang memadai tentang seksual. Ketidaksiapan remaja menghadapi perubahan dalam dirinya termasuk dorongan seks mulai meningkat dan sulit dikendalikan, tidak jarang hal tersebut menyebabkan konflik pada diri remaja. Keadaan tersebut diperberat dengan adanya kemudahan remaja mengakses informasi tentang seks yang keliru melalui media cetak dan elektronik (Sarwono, 2006).

Hasil diskusi dengan orang tua pada remaja pria dan wanita usia 10-24 tahun, menunjukkan bahwa ada $46 \%$ remaja lebih banyak berdiskusi KRR dengan ibunya dibanding dengan ayahnya sebanyak $17 \%$. Hasil yang lain menunjukkan bahwa remaja lebih sedikit $38,2 \%$ berdiskusi dengan orang tua hanya dibanding dengan teman sebayanya sebanyak $54,4 \%$. Seseorang yang dianggap penting oleh remaja, akan diharapkan persetujuannya setiap gerak dan tingkah laku, seseorang yang tidak ingin dikecewakan, atau seseorang yang berarti khusus bagi kita (significant others), akan banyak mempengaruhi pembentukan sikap (Ali dan Asrori, 2005).

Faktor-faktor yang mempengaruhi perilaku seksual remaja adalah hubungan orang tua remaja, tekanan negatif teman sebaya, pemahaman tingkat agama dan media pornografi memiliki pengaruh yang signifikan, baik secara langsung maupun tidak langsung terhadap perilaku seksual pranikah (Soetjiningsih, 2006). Paparan media massa, baik cetak (koran, majalah, buku-buku porno) maupun elektronik (TV, VCD, Internet) mempunyai pengaruh secara langsung maupun tidak langsung pada remaja untuk melakukan hubungan seksual pranikah (Astuti, 2009).

Berdasarkan penelitian yang dilakukan oleh Sudardi (2010) tentang hubungan media dengan perilaku seksual bebas pada remaja di Kota Surabaya bahwa informasi dari media yang saat ini sudah sedemikian canggih dan berkembang pesat berhubungan erat dengan perilaku remaja khususnya dalam perilaku kesehatan reproduksi. Menurut hasil 
penelitian Damayanti (2007), 5 dari seratus pelajar setingkat SMA di Jakarta telah melakukan hubungan seksual sebelum menikah. Menurutnya perilaku seksual pranikah itu cenderung dilakukan karena pengaruh teman sebaya yang negatif (Heru, 2007). Data Depkes RI (2006), menunjukkan jumlah remaja umur 10-19 tahun di Indonesia sekitar 43 juta $(19,61 \%)$ dari jumlah penduduk. Sekitar satu juta remaja pria (5\%) dan 200 ribu remaja wanita $(1 \%)$ secara terbuka menyatakan bahwa mereka pernah melakukan hubungan seksual.

Penelitian yang dilakukan oleh Badan Koordinasi Keluarga Berencana Nasional bekerjasama dengan Pusat Penelitian Kependudukan dan Sumber Daya Manusia Universitas Syiah Kuala tahun 2005 terhadap pengetahuan, sikap dan praktik kesehatan reproduksi pada siswa SMA di Propinsi Nanggroe Aceh Darussalam. Dari kabupaten yaitu Kota Sabang, Kota Banda Aceh, Aceh Tenggara dan Aceh Tamiang sebanyak 3\% mengaku telah berhubungan seks dari 588 responden dengan rincian perkabupaten sebagai berikut : 3\% dari 101 responden di Kota Sabang, 6,2\% dari 194 responden di Kota Banda Aceh, 3,5\% dari 145 responden di Aceh Tenggara dan 0,7\% dari 148 responden di Aceh Tamiang. Kemudian sebanyak 49,32\% siswa sudah mempunyi kekasih dan 19,6\% siswa sudah pernah berciuman secara birahi (Astuti, 2009).

Berdasarkan beberapa hal tersebut di atas, maka peneliti merasa tertarik untuk meneliti lebih lanjut tentang Hubungan Sumber Informasi Kesehatan Reproduksi Dengan Perilaku Seksual Pada Pelajar SMA Negeri di Kota Sabang.

\section{Permasalahan}

Bagaimana hubungan sumber informasi kesehatan reproduksi (media massa, orang tua dan teman sebaya) dengan perilaku seksual pada pelajar SMA Negeri di Kota Sabang.

\section{Tujuan Penelitian}

Untuk mengetahui hubungan sumber informasi kesehatan reproduksi (media massa, orang tua dan teman sebaya) dengan perilaku seksual pada pelajar SMA Negeri di Kota Sabang tahun 2015.

\section{Manfaat Penelitian}

1. Sebagai bahan masukan bagi Dinas Kesehatan Kota Sabang untuk melaksanakan program penyuluhan kesehatan terutama untuk peningkatan program Kesehatan Reproduksi Remaja (KRR).

2. Sebagai bahan masukan bagi Dinas Pendidikan Kota Sabang untuk menentukan kebijakan dalam memberikan pendidikan kesehatan reproduksi kepada pelajar SMA.

3. Sebagai bahan masukan bagi pihak sekolah untuk mengawasi perilaku anak selama disekolah serta mengadakan razia berkala terhadap media seperti buku, gambar, HP yang mengandung unsur pornografi.

\section{METODE PENELITIAN}

\section{Jenis Penelitian}

Metode penelitian ini adalah penelitian survey dengan menggunakan rancangan cross sectional. Rancangan penelitian ini untuk mengetahui hubungan sumber informasi kesehatan reproduksi dengan perilaku seksual pada pelajar SMAN di kota Sabang tahun 2015.

\section{Lokasi dan Waktu Penelitian}

Penelitian ini dilakukan di SMA Negeri se-Kota Sabang. Penelitian ini dilakukan pada bulan Oktober 2015.

\section{POPULASI DAN SAMPEL}

\section{Populasi}

Populasi dalam penelitian ini adalah pelajar SMA Negeri, baik laki-laki maupun perempuan yang bersekolah di SMA Negeri se-Kota Sabang berjumlah 607 siswa.

\section{Sampel}

Sampel dalam penelitian ini adalah sebagian pelajar SMA Negeri di Kota Sabang sebanyak 113 pelajar. Teknik pengambilan sampel dalam penelitian ini menggunakan rumus Kothari dalam Murti (2006). Metode pengumpulan sampel menggunakan metode purposive sampling.

\section{Metode Pengumpulan Data}

Data yang digunakan dalam penelitian ini adalah data primer dan sekunder. Data primer adalah data yang diperoleh secara langsung oleh penulis dari subjek penelitian yaitu jawaban dari para responden. Data primer diperoleh dari hasil pengisian kuesioner yang telah disusun berdasarkan tujuan penelitian. Data sekunder adalah data yang diperoleh secara tidak langsung oleh penulis tetapi telah dikumpulkan dari pihak lain. Data sekunder dalam penelitian ini adalah studi pustaka dan dari internet.

\section{Uji Validitas dan Reliabilitas}

Data penelitian ini diambil dengan menggunakan kuesioner yang diisi sendiri oleh responden. Sebelumnya dilakukan uji coba kuesioner pada 25 orang pelajar yang bukan termasuk dalam penelitian ini.

Dari tabel $r$ dengan taraf signifikan 0,05 (5\%) menggunakan rumus df $=\mathrm{N}-2$, maka nilai $\mathrm{r}$ adalah 0,396 . Hasil analisa reliabilitas 13 pertanyaan media massa menunjukkan nilai $\mathrm{r}$ hasil minimal $=0,478$ dan maksimal $=$ 0,907 serta nilai Alpha $=0,953$, nilai-nilai $r$ hasil dan nilai Alpha pertanyaan media massa lebih besar daripada nilai $r$ tabel $(0,396)$, hal ini bermakna bahwa pertanyaan media massa tersebut valid dan reliable.

Pertanyaan orang tua terdapat 7 pertanyaan, hasil uji menunjukkan nilai $\mathrm{r}$ hasil minimal $=0,423$ dan maksimal $=0,890$ serta nilai Alpha $=0,905$, nilai-nilai $r$ hasil dan nilai Alpha pertanyaan orang tua lebih besar daripada nilai $r$ tabel $(0,396)$, hal ini bermakna bahwa pertanyaan orang tua tersebut valid dan reliable. Pertanyaan teman sebaya terdapat 11 pertanyaan, hasil uji menunjukkan nilai $\mathrm{r}$ hasil minimal $=0,707$ dan maksimal $=$ 
0,889 serta nilai Alpha $=0,963$, nilai-nilai $\mathrm{r}$ hasil dan nilai Alpha pertanyaan teman sebaya lebih besar daripada nilai $r$ tabel $(0,396)$, jadi dapat disimpulkan bahwa pertanyaan teman sebaya tersebut valid dan reliable.

Hasil analisa reliabilitas 8 pertanyaan perilaku seksual menunjukkan nilai $\mathrm{r}$ hasil minimal $=0,521$ dan maksimal $=0,861$ serta nilai Alpha $=0,900$, nilai-nilai $r$ hasil dan nilai Alpha pertanyaan perilku seksual lebih besar daripada nilai $\mathrm{r}$ tabel $(0,396)$, hal ini bermakna bahwa pertanyaan perilaku seksual tersebut valid dan reliable.

\section{Teknik Pengolahan Data}

Pengolahan data dilakukan dengan menggunakan program analisis statistik. Setelah data diperoleh kemudian dilakukan pengolahan data sebagai berikut :

a. Memeriksa data (editing)

b. Memberi kode (coding)

c. Memasukkan data (entry)

d. Menyusun data (tabulating)

\section{Metode Analisis Data}

Analisa data dilakukan dengan beberapa uji statistik memakai bantuan program komputer yaitu analisis univariat dan analisis bivariat.

\section{HASIL DAN PEMBAHASAN}

\section{Hubungan Sumber Informasi Media Massa dengan Perilaku Seksual}

Berdasarkan hasil penelitian diperoleh nilai prevalensi rasio $=0,257$ dengan interval kepercayaan $95 \%$ $(0,079-0,842)$ menunjukkan bahwa remaja yang mendapatkan informasi tentang kesehatan reproduksi dari media massa dengan kategori tinggi 0,2 kali kemungkinan tidak melakukan penyimpangan perilaku seksual dibandingkan dengan remaja yang tidak mendapatkan informasi tentang kesehatan reproduksi dari media massa dan hasil uji Chi Square diperoleh $\mathrm{p}$ value $=0,018$, yang berarti dapat disimpulkan bahwa ada hubungan yang bermakna secara statistik antara peran media massa dengan perilaku seksual.

Hal ini sesuai dengan pendapat Astuti (2009) yang mengatakan bahwa pengaruh media dan televisi sering kali ditiru oleh remaja dalam perilakunya seharihari. Misalnya saja remaja yang menonton film remaja yang berkebudayaan barat dan melihat perilaku seksual itu menyenangkan, kemudian hal itu ditiru oleh mereka tanpa memikirkan akibatnya, dan perbedaan kebudayaan serta norma-norma dalam lingkungan masyarakat yang berbeda.

Menurut penelitian Fitriana (2010) ada hubungan positif yang signifikan antara media pornografi dengan perilaku seksual pranikah pada remaja. Artinya semakin positif sikap terhadap media pornografi maka semakin tinggi perilaku seksual pranikah pada individu. Sebaliknya individu yang memiliki sikap negatif terhadap media pornografi maka semakin rendah perilaku seksual pranikah pada individu.

Soetjiningsih (2004) mengatakan media massa merupakan salah satu faktor yang berpengaruh terhadap pengetahuan, sikap dan perilaku seksual. Berbagai tayangan yang sangat menonjolkan aspek pornografi, setiap hari tayangan televisi semakin mempertontonkan adegan percintaan, ciuman, gaya pacaran remaja masa kini, mendorong munculnya budaya baru bagi remaja.

Pratiwi (2004) juga menyebutkan bahwa salah satu faktor yang sangat mempengaruhi remaja adalah pengetahuan dan informasi, ketika informasi seksualitas yang diharapkan pertama kali berasal dari orang tua ditutup-tutupi karena dianggap tabu, remaja akhirnya memilih sumber informasi dari media massa dan teman sebaya. Globalisasi informasi juga menyebabkan aksebilitas remaja terhadap pornografi menjadi lebih mudah, apalagi saat ini dukungan teknologi turut mempermudah remaja memperoleh informasi seperti penggunaan handphone dan internet untuk mendapatkan informasi pornografi.

Berdasarkan hasil penelitian yang diperoleh Damayanti (2009) sumber-sumber yang ada seperti internet, TV, HP, VCD, video porno, teman, radio, poster, koran, buku bacaan, majalah, dan brosur yang dapat mempengaruhi perilaku seks pranikah remaja. Remaja memperoleh informasi tersebut lebih banyak dari handphone dan internet. Biasanya mereka menonton bersama teman-temannya di sekolah dan di luar rumah. Sumber informasi yang diperoleh remaja lebih banyak diperoleh dari luar seperti internet, teman dan media dari pada orang tuanya

Media-media pornografi yang telah banyak beredar tersebut memiliki daya tarik sendiri bagi remaja karena penyajiannya yang mudah dipahami dan terdapat banyak pilihan. Tetapi apapun bentuk media pornografi setiap orang memiliki sikap dan perilaku yang berbeda terhadap sebuah persoalan. Terkait dengan fenomena pornografi yang menjadi bahan gunjingan hangat di masyarakat, remaja mempunyai sikap-sikap yang berbedabeda. Berdasarkan pemahaman yang beragam yang dikemukakan oleh para remaja, sikap mereka pun sesungguhnya juga beragam. Sikap itu tidak terpisahkan dengan pandangannya. Artinya, sikap para remaja sejalan dengan pandangannya masing-masing. Ada yang menyatakan bahwa pornografi itu merupakan sesuatu yang terbuka dan tidak layak dipertontonkan. Akan tetapi, hal itu harus dilihat dalam sebuah konteks siapa, di mana, bagaimana, dan sebagainya sehingga hal itu akan bergantung pada masing-masing orang. Itu artinya, pornografi sangat subjektif dan mereka bersikap bahwa itu kembali pada masing-masing individu (Bungin, 2001).

\section{Hubungan Sumber Informasi Orang Tua dengan Perilaku Seksual}

Berdasarkan hasil penelitian diperoleh nilai prevalensi rasio $=4,421$ dengan interval kepercayaan $95 \%$ (0,939-20,811) menunjukkan bahwa remaja yang mendapatkan informasi tentang kesehatan reproduksi dari orang tua dengan kategori tinggi 4,5 kali kemungkinan tidak melakukan penyimpangan perilaku seksual dibandingkan dengan remaja yang tidak mendapatkan informasi tentang kesehatan reproduksi dari orang tua dan hasil uji Chi Square diperoleh p value $=0,043$, yang berarti dapat disimpulkan bahwa ada hubungan yang bermakna 
secara statistik antara peran orang tua dengan perilaku seksual.

Hasil penelitian ini sejalan dengan Sabatini (2011) yang menyatakan bahwa remaja yang memiliki hubungan baik dengan orang tuanya lebih rendah kemungkinannya melakukan hubungan seksual dibandingkan dengan remaja yang tidak memiliki hubungan erat dengan orang tuanya. Selain ini kualitas komunikasi orang tua dan anak dapat menghindari remaja dari perilaku seksual pranikah. Hal ini dikarenakan antara anak dan orang tua terjalin hubungan dan komunikasi yang intensif sehingga memungkinkan terjadinya diskusi dan pemecahan masalah bersama.

Hal ini juga sesuai dengan penelitian Soetjiningsih (2006), yang mengatakan bahwa faktorfaktor yang mempengaruhi perilaku seks pranikah paling tinggi adalah peran orang tua diikuti tekanan teman sebaya, religiusitas, dan eksposur media pornografi. Orang tua adalah tokoh penting dalam perkembangan identitas remaja, sehingga mereka harus dapat membangun hubungan dengan anak remajanya dan merupakan sistem dukungan ketika remaja menjajaki suatu dunia sosial yang lebih luas.

Menurut penelitian Darmasih (2009) peran keluarga berhubungan dengan perilaku seks pranikah remaja. Hubungan orang tua yang harmonis akan menumbuhkan kehidupan emosional yang optimal terhadap perkembangan kepribadian remaja dan sebaliknya, orang tua yang sering bertengkar akan menghambat komunikasi dalam keluarga, dan remaja akan melarikan diri dari keluarga. Keluarga yang tidak lengkap misalnya karena perceraian, kematian, dan keluarga dengan keadaan ekonomi yang kurang, dapat mempengaruhi perkembangan jiwa remaja. Komunikasi antara orang tua dengan remaja dikatakan berkualitas apabila kedua belah pihak memiliki hubungan yang baik dalam arti bisa saling memahami, saling mengerti, saling mempercayai dan menyayangi satu sama lain, sedangkan komunikasi yang kurang berkualitas mengindikasikan kurangnya perhatian, pengertian, kepercayaan dan kasih sayang di antara keduanya. Komunikasi yang menguntungkan kedua belah pihak, dalam hal ini antara orang tua dengan remaja adalah komunikasi yang timbal balik. Penelitian Hanifah (2013) menyimpulkan bahwa kontrol sosial orang tua merupakan salah satu yang mempengaruhi terjadinya perilaku seks pranikah pada remaja, serta ada faktor lain yang diduga mempengaruhi perilaku seks pranikah pada remaja, seperti kontrol diri remaja yang rendah, intensitas penggunaan internet, pergaulan, dan pengaruh teman sebaya. Kontrol sosial orang tua pada anak sangatlah penting bagi remaja untuk mengarahkan, memberikan nasehat, memberikan pujian atau hukuman atas perilaku remaja itu sendiri. Saat ini banyak orang tua yang kurang mengontrol pergaulan dan perilaku remaja. Sehingga terjadi kebimbangan dan keraguan remaja mengenai apa yang boleh dilakukan dan apa yang tidak boleh mereka lakukan. Pada penelitian ini juga ditemukan bahwa orang tua lebih sering menerapkan kontrol sosial di dalam keluarga dengan menciptakan sistem hukum. Sistem hukum ini bertujuan sebagai pengendalian aktivitas dan perilaku remaja.

Keluarga memiliki peranan dalam membentuk kepribadian dan mengembangkan sikap sosial yang baik dan perilaku yang terkontrol seorang remaja. Remaja yang dibesarkan dalam keluarga yang tidak harmonis mempunyai resiko kecenderungan yang besar untuk menjadi remaja yang melakukan tindakan-tindakan anti sosial. Selanjutnya hubungan komunikasi yang baik antara orang tua dan anak akan menciptakan saling memahami terhadap masalah-masalah keluarga, khususnya mengenai problematika remaja, sehingga akan berpengaruh terhadap sikap dan perilaku yang dibawa anak yang sesuai dengan nilai-nilai yang ditamankan kepada anak oleh orang tua mereka.

\section{Hubungan Sumber Informasi Teman Sebaya dengan Perilaku Seksual}

Berdasarkan hasil penelitian diperoleh nilai prevalensi rasio $=0,253$ dengan interval kepercayaan $95 \%$ $(0,080-0,805)$ menunjukkan bahwa remaja yang mendapatkan informasi tentang kesehatan reproduksi dari teman sebaya dengan kategori tinggi 0,2 kali kemungkinan tidak melakukan penyimpangan perilaku seksual dibandingkan dengan remaja yang tidak mendapatkan informasi tentang kesehatan reproduksi dari teman sebaya dan hasil uji Chi Square diperoleh p value $=0,014$, yang berarti dapat disimpulkan bahwa ada hubungan yang bermakna secara statistik antara peran teman sebaya dengan perilaku seksual.

Hasil penelitian ini sesuai dengan penelitian Astuti (2009) yang mengatakan bahwa teman sebaya berpengaruh terhadap perilaku seksual. Hal tersebut terjadi karena pada masa remaja kedekatan dengan teman sebaya sangat tinggi, selain ikatan teman sebaya menggantikan ikatan keluarga, mereka juga merupakan sumber simpati, pengertian dan saling berbagi pengalaman.

Berdasarkan hasil penelitian Maryatun (2013) menunjukkan bahwa remaja yang mendapatkan peran teman sebaya dalam informasi seksualitasnya beresiko berperilaku seksual pranikah dibandingkan remaja yang tidak memperoleh informasi seksualitas dari teman sebaya. Remaja yang melakukan perilaku seks pranikah dapat termotivasi oleh pengaruh kelompok (teman sebaya) dalam upaya ingin menjadi bagian dari kelompoknya dengan mengikuti norma-norma yang telah dianut oleh kelompoknya (melakukan perilaku seks pranikah). Selain itu, didorong oleh rasa ingin tahu yang besar untuk mencoba segala hal yang belum diketahui.

Menurut penelitian Suwarni (2009), ada pengaruh perilaku teman sebaya terhadap perilaku seksual remaja baik secara langsung maupun tidak langsung melalui niat berperilaku seksual. Temuan ini sejalan dengan teori psikologi perkembangan remaja yang menyatakan, dalam proses pendewasaan, pengaruh keluarga telah bergeser menjadi teman sebaya. Hal ini dibuktikan dengan besarnya pengaruh langsung dari teman sebaya negatif terhadap perilaku berisiko, sedangkan pengaruh keluarga berdampak tidak langsung. Teman 
sebaya sangat besar pengaruhnya bagi kehidupan sosial dan perkembangan diri remaja

Dukungan teman sebaya menjadi salah satu motivasi dan pembentukam identitas diri seorang remaja dalam melakukan sosialisasi, terutama saat dia menjalin asmara dengan lawan jenis (Prihatin, 2007). Teman sebaya dalam pergaulan kadang kala menjadi salah satu sumber informasi yang cukup signifikan dalam membentuk pengetahuan kesehatan reproduksi dan perilaku seksual dikalangan siswa, bahkan informasi tersebut bisa menimbulkan dampak negatif karena informasi yang mereka peroleh hanya melalui media massa (film, DVD atau televisi), maupun pengalaman diri sendiri (Ajik, 2004).

Menurut penelitian Damayanti (2011) remaja yang mempunyai teman pernah melakukan hubungan seksual cendrung 3 kali lebih tinggi untuk berprilaku seksual pranikah dari pada remaja yang tidak punya teman yang melakukan hubungan seksual. Teman sebaya yang tidak berperilaku seksual pra nikah berat (hubungan seksual) juga akan dapat mencegah perilaku seksual pranikah resiko berat remaja. Remaja yang berkomunikasi tidak aktif dengan teman sebaya akan mempunyai peluang terproteksi untuk berperilaku seksual beresiko berat dibandingkan berkomunikasi aktif dengan teman sebaya. Berarti teman sebaya (yang mendukung perilaku seksual pra nikah) yang tidak aktif berkomunikasi, akan dapat mencegah remaja berperilaku seksual pranikah resiko berat.

Remaja mempunyai kecenderungan untuk mengadopsi informasi yang diterima dari teman sebaya tanpa memiliki dasar informasi yang signifikan dari sumber yang lebih bisa dipercaya. Informasi dari temanteman tersebut dalam hal ini sehubungan dengan perilaku seksual pranikah, tak jarang memunculkan rasa penasaran dalam diri remaja. Untuk menjawab pertanyaan tersebut dan membuktikan kebenaran informasi yang diterima, maka tak jarang remaja melakukan perilaku seksual pranikah itu sendiri.

\section{KESIMPULAN}

Berdasarkan hasil penelitian dan pembahasan, maka dapat diambil kesimpulan sebagai berikut :

1. Sumber informasi kesehatan reproduksi pada media massa memiliki peran tinggi dengan perilaku seksual $(80,5 \%)$, orang tua memiliki peran tinggi dengan perilaku seksual $(61,1 \%)$ dan teman sebaya memilki peran tinggi dengan perilaku seksual $(76,1 \%)$.

2. Berdasarkan tabulasi silang menunjukkan variabel yang berhubungan antara sumber informasi kesehatan reproduksi dengan perilaku seksual adalah peran media massa $(\mathrm{p}=0,018)$, peran orang tua $(\mathrm{p}=0,043)$ dan peran teman sebaya $(\mathrm{p}=0,014)$.

\section{SARAN}

1. Sekolah dapat bekerja sama dengan guru pengajar dan guru BP untuk mengawasi perilaku anak selama disekolah serta menyampaikan kepada orang tua supaya selalu mengawasi perilaku anak selama diluar sekolah.

2. Kepada pihak sekolah agar sering mengadakan razia berkala terhadap media seperti buku, gambar, HP yang mengandung unsur pornografi.

3. Kepada Dinas Pendidikan untuk menentukan menentukan materi kesehatan reproduksi yang sesuai untuk disampaikan agar pelajar mendapat pengetahuan yang benar mengenai kesehatan reproduksi.

4. Kepada Dinas Kesehatan agar sering melakukan penyuluhan kesehatan reproduksi kepada pelajar terkait dengan Kesehatan Reproduksi Remaja (KRR)

\section{DAFTAR PUSTAKA}

Ali, M., dan Asrori, M., 2005. Psikologi Remaja, Jakarta: PT. Bumi Aksara.

Astuti, J., 2009. Pengaruh Karakteristik Siswa dan Sumber Informasi Terhadap Kecenderungan Melakukan Hubungan Seksual Pranikah pada Siswa SMA Negeri di Banda Aceh, Tesis, Medan: Universitas Sumatera Utara.

BKKBN dan Pusat Penelitian Kependudukan dan Sumber Daya Manusia, 2005. Pengetahuan Sikap dan Praktik Kesehatan Reproduksi Remaja Bagi Siswa SMA di Provinsi NAD, Laporan Akhir Hasil Penelitian, Banda Aceh.

Bungin, B, 2001. Erotika Media Massa, Surakarta: Muhamaddiyah University Press.

Damayanti, Y., Lestari, Y., dan Ramadani, M., 2011.Peran Teman Sebaya Terhadap Perilaku Seksual Pranikah Siswa SLTA Kota Bukit Tinggi. Jurnal Kesehatan Masyarakat, September 2011Maret 2011, Vol. 6, No. 1.

Darmasih, R., 2009. Faktor Yang Mempengaruhi Perilaku Seksual Pranikah pada Remaja SMA di Surakarta, Skripsi.

Depkes RI, 2006. Lebih 1,2 Juta Remaja Indonesia Sudah Lakukan Seks Pranikah, diakses 25 mei 2015, $\quad$ http://karodalnet.blogspot.com/2008 /08/lebih12jutaremajaindonesiasudh. html.

Fitriana. N. G., 2010, Hubungan Pengetahuan dan Sikap Tentang Seks Pranikah dengan Perilaku Seksual Pada Siswa SMK XX Semarang : Makara Kesehatan, Vol. 10, no. 1, juni 2010: 29-40

Hanifah, F., 2013. Hubungan Kontrol Sosial Orang Tua dengan Perilaku Seksual Pranikah Remaja Kelurahan Batang Arau Kecamatan Padang Selatan, Spektrum PLS, Vol. 1, No.2.

Maryatun, 2013. Peran Teman Sebaya Terhadap Perilaku Seksual Pranikah pada Remaja di SMA Muhammadiyah 3 Surakarta, GASTER Vol. 10, No. 1.

Pratiwi, 2004. Pendidikan Seks Untuk Remaja. Yogyakarta: Tugu Publisher.

Prihatin, T.W., 2007. Analisis Faktor-faktor yang Berhubungan dengan Sikap Siswa SMA Terhadap 
Hubungan Seksual (Intercourse) Pranikah di Kota Sukoharjo, Tesis, Semarang: Universitas Diponegoro.

Sabatini, B.C., 2011. Hubungan Antara Pengetahuan Kesehatan Reproduksi dan Persepsi Tentang Peran Keluarga dengan Perilaku Seksual pada Remaja di Kota Surakarta, Tesis, Surakarta: Universitas Sebelas Maret.

Sarwono, S.W., 2006. Psikologi Remaja, Jakarta: Raja Grafindo Persada.

Soetjiningsih, 2004. Tumbuh Kembang Remaja dan Permasalahannya, Jakarta: Sagung Seto.
Soetjiningsih, 2006. Remaja Usia 15 - 18 Tahun Banyak Lakukan Perilaku Seksual Pranikah. Diakses 20 mei 2015.

http://www.ugm.ac.id/index.php?page=rilis\&artikel $=1659$

Sudardi, 2010. Pengaruh Media Terhadap Perilaku Seks Bebas Remaja di Kota Surabaya, Artikel Kesmas, Malang: Universitas Muhammadiyah.

Suwarni, L., 2009. Monitoring Parental dan Perilaku Teman Sebaya Terhadap Seksual Remaja SMA di Kota Pontianak, Jurnal Promosi Kesehatan Indonesia, Vol.4, No. 2. 